\title{
A Project Interface Buffering Model for Application Engineer Management
}

\author{
P. H. Cheng ${ }^{1,2}$, T. N. Chien ${ }^{2}$, C. H. Chien ${ }^{2}$, S. J. Chen ${ }^{2}$, and J. S. Lai ${ }^{1}$ \\ ${ }^{1}$ Information Systems Office, \\ National Taiwan University Hospital and National Taiwan University College of Medicine, Taipei, Taiwan \\ ${ }^{2}$ Graduate Institute of Electronics Engineering and Department of Electrical Engineering, \\ National Taiwan University, Taipei, Taiwan
}

\begin{abstract}
This paper describes our proposed Project Interface Buffering Model (PIBM) which helps to reduce and smooth the many conflicting problems among system engineers, application programmers, system qualifier and system analysts who have participated in the IBM mainframe rightsizing project at National Taiwan University Hospital (NTUH). In fact, the PIBM can be used to relax or even solve the traditional conflict burden between the Vertical Formal Organization Management (VFOM) and Horizontal Cross-department Project Management (HCPM), and then to create an acceptable environment. First of all, an overall description on the current hospital status and problem is presented. Then, the interface model is proposed and its current implementation shown. Related effects on the organization perspective and engineer careers are also discussed.
\end{abstract}

Keywords-Design of environment, management of technology, project management, reengineering

\section{INTRODUCTION}

\section{A. Reengineering}

Frankly, the mainframe rightsizing process is hard to plan and needs enough patients for all of the participants. Based on the experiences from the other successful rightsizing stories, we realize that it is necessary for us to capture this opportunity and tightly couple the rightsizing process with department reengineering.

In 2003, Aken [1] said "Department management as part of the methodology are reengineering the project lifecycle process to a concurrent team-based approach and implementing a performance measurement scorecard for the department." $\mathrm{He}$ proposed the following transformation methodology steps for the reengineering department. They were (a) understanding the need for change, (b) creating the infrastructure for change, (c) analyzing the current situation, (d) setting the direction for change, (e) defining improvement initiatives, (f) deploying and implementing initiatives, and $(\mathrm{g})$ reviewing progress and performance.

\section{B. Interface}

In 1984, Tanenbaum's book [2] illustrated the virtual machine concept. Furthermore, Patterson and Hennessy [3] promoted the interface concept in their book in 1997. All of them convey the interface concept to all of the computer students and engineers. What is the 'interface'?
From the Longman dictionary [4], we found that the definition of 'interface' is a noun and has been defined as "1. the way in which you see the information from a computer program on a screen, or how you type information into the program; 2 . the part of a computer system that connects two different machines; 3 . the way in which two subjects, events etc affect each other; 4 . the surface where two things touch each other." It also is a verb and has definitions as " 1 . if you interface two parts of a computer system, or if they interface, you connect them; 2. if two people or groups interface with each other, they communicate with each other and work together."

Obviously, we could borrow the interface concept from the computer organization field to the engineering management field. The former one is used between two computer subjects, the latter one is laying between two groups of people.

Fortunately, Dasher [5] tried to use interface to solve the problems which occurs within the project management. He said that "A clear understanding of the interfaces, and the supporting role by the systems engineer (SE), is critical to effective execution of any project/program" in 2003. He also said that "A strong, healthy relationship between the $\mathrm{SE}$ team, represented by the computer engineer (CE), and the project manager (PM), is an absolute must. Then, communicate, communicate, communicate ... with the entire team." However, Dasher only focused on and mentioned the system engineer role within the project management team.

Furthermore, we proposed a collaborative healthcare information system model in the beginning of 2004 [6] and tried to move our eyes on the project management and affection within this paper. We divide our developers into four teams: (a) interface integration team (IIT), (b) system analysis team (SAT), (c) system programming team (SPT), and (d) system qualification team (SQT). We named them as a software collaborative team (SCT).

\section{Standardization}

On the other hand, Rada and Craparo [7] used standardization management to handle the software engineering project. These standards at least include Capability Maturity Model Integration (CMMI), Microsoft Solutions Framework (MSF), etc. They also said that "Companies must choose standards that fit with their internal corporate culture." Furthermore, "If an organization has many software engineering teams, then some standardization of methods across teams is important." 


\section{Personality}

Besides, Gorla and Lam [8] illustrated the analysis on personality type can help take the guesswork out when we are putting together a high-performance software project team. Meanwhile, Chen and Lin [9] also enhanced this idea and said that "To ensure a successful multifunctional team, it is important to understand the characteristics of team members." In 1999, Chen, Tomaso, and Fassis [10] also said that "Self-interest is not the only influence on employee reactions, and perhaps not the most important one. The values employees held, in this case regarding the importance of competition, had the most significant effect." Therefore, we should try to understand the personality of team members. Furthermore, the project manager could try to know the self-interest of the team members if necessary.

\section{E. Management Types}

Basically, the vertical formal organization management (VFOM) is so traditional that most of the colleagues will follow up the orders issued by the direct manager. Undoubtedly, all of the colleagues and managers like this kind of management model.

On the contrary, the horizontal cross-department project management (HCPM) is highly dynamic organized by different specialists which originally allocated at different departments. We know that most of the project managers do not like this kind of the management model. The problems might be implicit and hide below the meeting table. However, the problems do not be solved and most of the project managers might suffer the hardship case by case. If the project manager could self-adjust his own mood and keep his temper smooth, then the suffering will be temporarily suppressed. Nevertheless, the above optimization situation does not possibly occur every time.

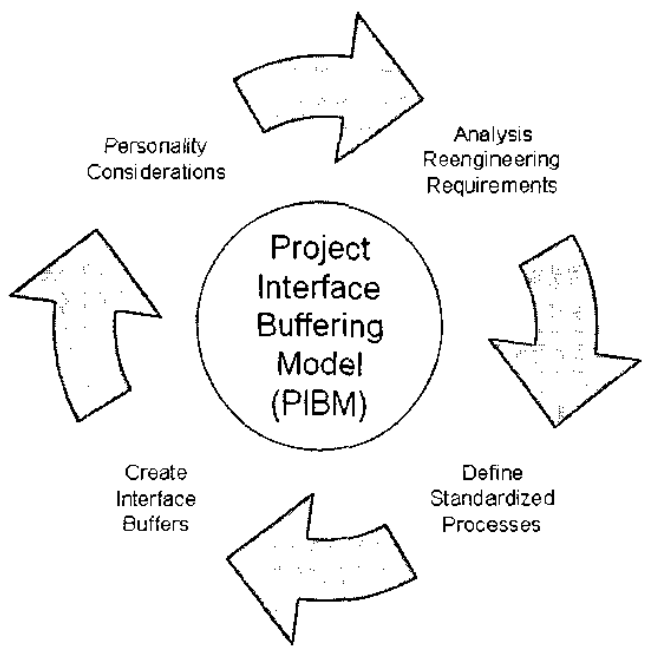

Fig. 1. Project interface Buffering Model (PIBM).

\section{METHODOLOGY}

Based on the above concepts, we try to construct a rightsizing team with sixty-five team members and work together under a centralized reengineering policy, with standardization processes, clear communication interfaces, and personality considerations. We are also dynamically adjusting the tasks of our team members in order to execute the related tasks effectively. Fig. 1 illustrated the relationship of the process steps.

\section{A. Analyze Reengineering Requirements}

Recently, our Information Systems Office at National Taiwan University Hospital (NTUH) tried to focus on and solve the problems which occur from the conflict between VFOM and HCPM. We illustrate the real cases which are aroused inside the NTUH environment and describe our solution to solve or alleviate the suffering from the executions. The execution result of our solution might be a little bit different from different nations. Otherwise, it is so straightforward that every organization might adopt it.

Fig. 2 illustrated the basic conflict between the VFOM and HCPM model. We divided the hospital departments into three department groups depending on their properties of medical services. That is, they are divided into medical department group (MDG), medical supporting department group (MSDG), and administration department group (ADG). Obviously, the MDG includes many clinical departments, such as internal medicine department, surgical department, dental department, pediatrics department, etc. The MSDG supports the services of medical department and acts as second line for medical services. It might include laboratory department, observation department, pharmacy department, nutrition department, etc. The ADG includes some general office administration departments, such as personnel department, accounting department, general services department, etc.

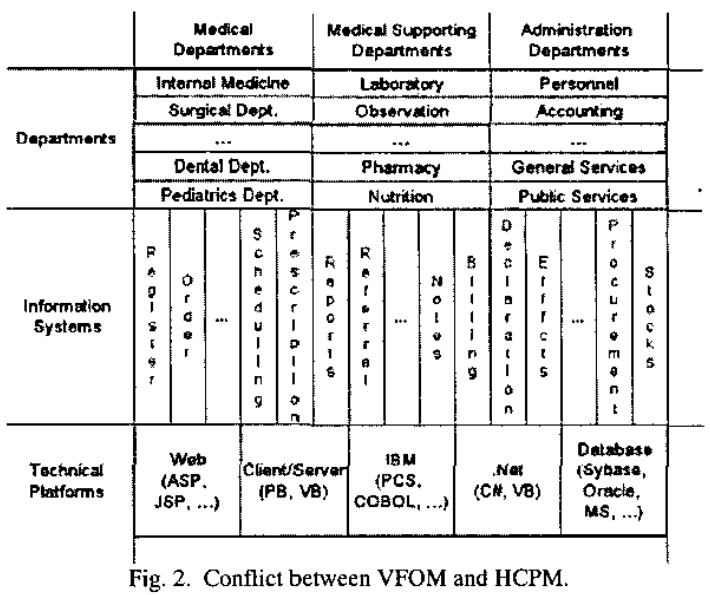

From the view of the information system, we could group the information systems according to their usage by the above three department groups. Consequently, the 
MDG might use the register information system, order information system, scheduling information system, prescription information system, etc. The MSDG might use the reporting information system, referral information system, notes information system, billing information system, etc. The ADG might use the declaration information system, effects information system, procurement information system, stocks information system, etc.

Clearly, we know that the departments and technical platforms belong to HCPM and the information systems to VFOM. Furthermore, the related healthcare information systems concepts and models could be referred by [11][12][13].

\section{B. Define Standardized Processes}

Since the Information Systems Office of NTUH had past the Det Norske Veritas (DNV) official management system certification and followed the ISO-9001:2000 standard processes from Spring 2001. There are many well-defined, official documents and process flows could be followed by the rightsizing team members. In order to satisfy the requirements of the rightsizing management, we dynamically modify and optimize some of the official process flows by necessary.

\section{Create Interface Buffers}

Fig. 3 illustrated our solution where we used two interfaces to solve basic conflict between the VFOM and HCPM models. Harmoniously, these two interfaces will smooth the sufferings of two management models. There are two interface buffers, (a) the coordination interface buffer (CIB) between the departments and information systems, (b) the technical interface buffer (TIB) between the information systems and technical platforms.

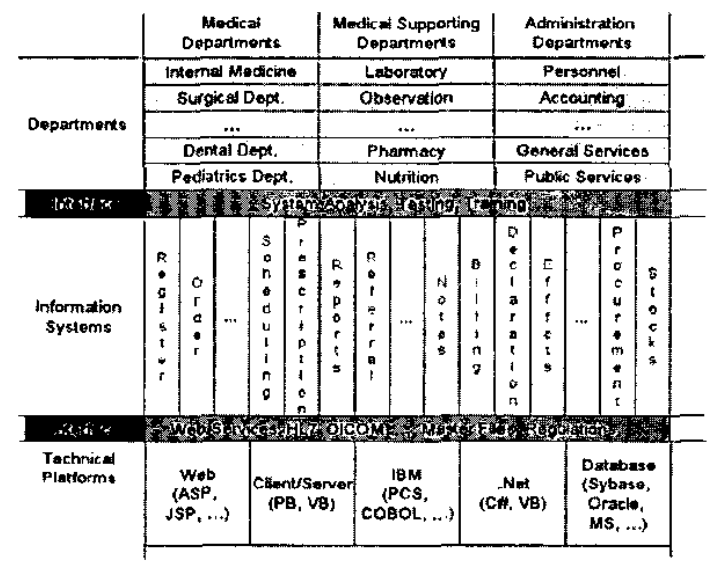

Fig. 3. Interface buffers between the VFOM and HCPM

The top interface buffer, CIB, will be grouped as another team to act as the system analysts, system testing, and system training. Frankly, NTUH does not strictly follow the formal system development life cycle (SDLC).
That is, sometimes, the system analyst, system programmer, and system tester might be the same colleague. If possible, we will try to separate the above three tasks into different colleagues. However, the concept is quite easy and the execution is very hard to fulfill completely. The team members will be managed through a manager directly who acts as the contact person between the department contact windows and system programmers.

Normally, we will ask for the system analyst to write down the user manual after the completion of system analysis task. The user manual will be reviewed and confirmed by the manager, department contact window, and related committees. Then the user manual will be refined and act as the training document of related system and sent to another education department to setup the system education schedules. Meanwhile, the user manual will be accepted by the related system programmers to follow the already decided schedule to implement the related system on time.

The bottom interface buffer, TIB, will be a team which focus on the advanced technical parts which directly managed by the manager. The team members should realize that it is hard to represent their performance from tasks representations. On the contrary, the loading of this team is so high that team leader should suffer more sufferings from different system analysts. Meanwhile, the members should keep their technical skills at the crest of latest computer technology wave.

\section{Take Care of Personality}

Although most of the team members had worked together for a long time, the project manager might not quite understand the real thoughts of everyone. To release the conflicts among team members, project manager should try to gather the latest thoughts from all of the team members. We know the personnel department will routinely survey the colleagues for their future career plans within most of the organizations, however, it is also worthy for project manager to waste some time to understand the deep minds of his team members within the project scope. In fact, we schedule a short routine chatting about 15 minutes everyday with a specific member and do not let all of the members know the schedule. Imperceptibly, manger will enter that member's life gradually.

Before we assign team members to the specific groups, we do a small survey to all of the team members and let everyone to circle their desired roles in priority, even to write down their career plans within three years. The survey questions for the rightsizing team at least include name, birthday, sex, seniority, favor roles with priority, the most favor role within one year, the most favor role within three year, the most wanted skill within one year, programming skills with priority, programming skills with capability self-evaluation, and desire to advance to higher school. 
In the priority survey of programming skills, we list all the programming languages used in our information systems. They at least include IBM COBOL, IBM PCS, Visual Basic, PowerBuilder, C, Stored Procedure, ASP, JavaScript, JSP, Java Servlet, C\#.Net, ASP.Net, VB.Net, and Delphi. After the analysis of survey, we use the favor roles with priority item to assign the appropriate tasks to all of the team members.

\section{RESULTS}

Table I illustrated part of the survey results of the Application Systems Division I which covers twenty-six programmers. Inside Table I we just count the number and let the priority as our future reference for task assignments. It always lets a project manager smile after collecting the result papers from the survey. Based on our experiences, most of the team members are corporately and welcome the related survey. Otherwise, it is important that project manger should do some changes within the team after the survey and do guarantee that the original survey data will not release the personal result to any other one.

After the survey of the future plan from one of our division, Application Systems Division I, the job assignments become more smoothly and highly acceptable by most of the engineers. Under such survey results, it is possible for us to process the department reengineering frequently. In order to meet the manpower requirements of the rightsizing project, currently, we had two major changes (2004/02/25 and 2004/06/18) and four minor changes within seven months this year. Table II illustrated these changes with the PIBM methodology.

\section{TABLE I}

PART OF THE SURVEY RESULTS OF APPLICATION SYSTEMS DIVISION I

\begin{tabular}{lll}
\hline Questions & Task Descriptions & Survey Result \\
\hline Favor roles & Information Management & 4 \\
with priority & System Management & 8 \\
& Project Management & 12 \\
& System Analysis & 20 \\
& System Design & 20 \\
& System Quality Assurance & 14 \\
& Application Programming & 20 \\
& Art Programming & 8 \\
& Application Training & 17 \\
& Public Affairs Management & 13 \\
& Others & 2 \\
\hline
\end{tabular}

Distinctly, we extend the PIBM methodology from Application System Division I to another two divisions (Application System Division II and Education Division) in our department. Although we already have another System Administration Division for managing the system administration, hardware maintenance, etc., we insert a TIB to implement and manage the information exchange kernel programs. Team members of this interface buffer should have professional skills to handle tough tasks. In addition, we combine the project management and system analysis tasks together at ClB. That is, we ask for the system analyst should manage the project at the same time.

TABLE II

REENGINEFRING TRANSITIONS OF APPLICATION SYSTEMS DIVISIONS I \& II AND EDUCATION DIVISION

\begin{tabular}{|c|c|c|c|c|c|}
\hline \multirow{3}{*}{ Questions } & \multirow{3}{*}{ Task Descriptions } & \multicolumn{4}{|c|}{ Task Distribution } \\
\hline & & \multirow{2}{*}{$02 / 25$} & \multicolumn{3}{|c|}{$06 / 18$} \\
\hline & & & $I^{2}$ & $11^{b}$ & $\mathrm{E}^{\mathrm{c}}$ \\
\hline \multirow{10}{*}{$\begin{array}{l}\text { Favor roles } \\
\text { with priority }\end{array}$} & Information Management & 1 & 1 & 1 & 1 \\
\hline & System Management & 3 & 2 & 3 & 0 \\
\hline & $\begin{array}{l}\text { Project Management } \\
\text { System Analysis }\end{array}$ & 9 & 9 & 2 & 0 \\
\hline & System Design & 0 & 0 & 9 & 0 \\
\hline & System Quality Assurance & 0 & 0 & 2 & 0 \\
\hline & Application Programming & 13 & 13 & 0 & 0 \\
\hline & Art Programming & 0 & 0 & 0 & 0 \\
\hline & Application Training & 0 & 0 & 0 & 4 \\
\hline & Public Affairs Management & 0 & 0 & 0 & 3 \\
\hline & Others & 0 & 0 & 0 & 0 \\
\hline \multirow{2}{*}{$\begin{array}{l}\text { Team } \\
\text { Members }\end{array}$} & & 26 & 26 & 17 & 8 \\
\hline & & & 51 & & \\
\hline
\end{tabular}

\section{DISCUSSION}

The first process step is the most important part of this model, because the golden rule, garbage-in-garbageout, of the computer science. Before a manager kicks off the PIBM process, it is necessary for the manger to intently observe the organization vision, the working environment, the minds of team members, the information systems, and the necessary skills, etc. The data collection of above information is so unstructured that the manager should try to categorize the collected data and draw a diagram to let all of the team members understand what he wants to reengineer the department. In fact, little of the engineer likes blind task assignment. That is, most of them like a clear definition of task assignment.

From the second process step, we know that the ISO 9001:2000 might be out-of-date and not quite suitable to software engineering management for some reasons. Hence, we will try to allocate some budget and find a good cut-in time to transfer our standardize process definition and management to CMMI.

The third process step is trying to insert interface buffers to the conflict of labor divisions. Therefore, it is necessary and important for manager to exactly utilize the appropriate survey to collect the correct data from all of your team members. If a manager wants to obtain an acceptable and predictable result in the future, then he has to use an objective view to analyze the collected data. Regularly, it becomes a nightmare for a manager to assign the tasks of the shadow area between the information systems and skill platforms. If possible, the manger has to guarantee some future credits in advance for members who accept the tasks of interface buffers. Although we try 
to obtain a reconciliatory environment from our PIBM methodology, the team member minds and user task requirements are changing every day. Comparatively, a manager should observe the status of the team members and try to fine tune their tasks frequently. On the contrary, a manager should not create too many interface buffers to increase the communication frequency between the team members and to decrease the performance of the team works. The advantages of this process implementation are listed as follows.

(1) Delight the users with clear and identical statement.

(2) Decrease the communication frequency of contact between the VFOM and HCPM models.

(3) Build the distinct and explicit right and duty cut.

(4) Cultivate the possible future managers to train them with different integrated administrative matters.

(5) Integrate the complex flows after formal discussion meeting and confirming them with the direct chief of information officer (CIO)

There are some interesting results from the fourth process step. From the survey results, a manager could understand the team members deeper. If a manger has available time, we also suggest that this manager should visit all of the team members individually and sincerely.

\section{CONCLUSION}

Basically, we divide our current healthcare departments into three functional groups. They are MDG, MSDG, and ADG. No matter how we group these departments, it is impossible for us to dismiss the chaos phenomena of the function assignments between VFOM and HCPM. All we could do is to alleviate the conflict status by using the PIBM methodology. Anyhow, buffer likes a car bumper can insure a driver far away from dangers. One buffer is better than no buffer. It is true inside both of the car accident prevention and engineering management.

\section{ACKNOWLEDGMENT}

The authors would like to acknowledge the suggestions from Prof. J. L. Chen, and Prof. S. H. Lee, Information Systems Office, NTUH and especially Prof. F. P. Lai, vice superintendent of NTUH for his major input in defining mission, vision, and improvement strategies for the Department. The authors would also like to thank C. H. Yang and J. M. Han for their contributions to this effort.

\section{REFERENCES}

[1] E. M. Van Aken, D. Van Goubergen, and G. Letens, "Integrated enterprise transformation: case application in engineering project work in the Belgian Armed Forces,"
Engineering Management Journal, vol. 15, no. 2, pp. 3-16, June 2003.

[2] A. S. Tanenbaum, Structured Computer Organization, $2^{\text {ad }}$ Ed. Englewood Cliffs, NJ: Prentice-Hall, 1984, pp. 1-18.

[3] D. A. Patterson and J. L. Hennessy, Computer Organization and Design: The Hardware / Software Interface, $2^{\text {nd }}$ Ed., Morgan Kaufmann, CA, 1997, pp. 1-50.

[4] Della Summers, Longman dictionary of contemporary English, New Ed., Pearson Education: England, 2003, pp. 849

[5] G. T. Dasher, "The interface between systems engineering and program management," Engineering Management Journal, vol. 15, no. 3, pp. 11-14, Sept. 2003.

[6] P. H. Cheng, C. H. Yang, H. S. Chen, S. J. Chen, and J. S Lai, "Another HL7 usage in collaborative healthcare information systems," Proc. of the $26^{\text {th }}$ Annual Int'l Conf. IEEE Engineering in Medicine and Biology Society, EMBC'04, San Francisco, CA, USA.(Accepted)

[7] R. Rada and J. S. Craparo, "Standardizing management of software engineering projects," Knowledge Technology, and Policy, vol. 14, no. 2, pp. 67-77, 2001.

[8] N. Gorla and Y. W. Lam, "Who should work with whom? Building effective software project team, "Communications of the ACM, vol. 47, no. 6, pp.79-82, June 2004.

[9] S. J. Chen and L. Lin, "Modeling team member characteristics for the formation of a multifunctional team in concurrent engineering," IEEE Trans. on Engineering Management, vol. 51, no. 2, pp. 111-124, May 2004.

[10] C. C. Chen, N. Di Tomaso, and G. F. Farris, "Attitudes toward organizational change: effects of self-interest, competitive values, and ethnicity," IEEE Trans, on Engineering Management, vol. 46, no. 4, pp. 399-406, Nov. 1999.

[11] E. Ginzberg, W. Balinsky, and M. Ostow, Home Health Care: Its Role in the Changing Health Services Market, Rowman \& Ailanheld, USA, 1984.

[12] R. S. Dick, E. B. Steen, and D. E. Detmer, "A Progress Report on Computer-Based Patient Records in the United States," The Computer-Based Patient Record: An Essential Technology for Health Care, Revision Ed., National Academy Press, Washington D. C. USA, pp. 1-41, 1997.

[13] D. W. Forslund and D. G. Kilman, The impact of the Global Extensible Electronic Health Record, Managing Healthcare Information Systems with Web-Enabled Technologies, IDEA Group Publishing, Hershey, USA, pp. 3-13, 2000. 